leute gekommen ist. (luthmerig offenbar.)

Miest. Der nebel. Miestig. Nebelich.

*Pesel. Die stube im hause. (pesel stube.)

Specken. Der landweg nach der geest zu.

Tier. Guter muth. Gute gesundheit. Up sin tier sin. Gutes muthes seyn. Sich wohl befinden.

HALLE A. S., den 15. august 1891. OTTO BREMER.
Tünteln. Zaudern. Verzögern.

*Upweer. Wenn nach vielem regen und triben wolken der himmel sich aufklärt.

*Weersdage. Sommertage.

*Wrange. Eine befestigung, die in einem graben gemacht wird, um das obere wasser aufzuhalten, und das untere desto bequemer auszuschöpfen.

\title{
ZU DEN MURBACHER HYMNEN.
}

Eine erneute collation der hs., die ich im vorigen herbst vorzunehmen gelegenbeit hatte, hat folgende berichtigungen meines textes ergeben: XVIII, 4, 2 lies kadenne für kadenni. $\mathrm{XX}, 7,2$ hat die hs. rih (ri im ligatur) für sih. XXI, 4, 4 lies lihcamo fur lihamo. XXII, 8, 2 urchundono fur urchondono. XXIV, 1, 1 cuninc für cuning, 14, 4 stanlant's für standant's.

LEIPZIG, 15. juli 1892.

E. SIEVERS. 